\title{
Development of a Design System for the Sprout Tide-type Irrigation Device
}

\author{
GUO Yi
}

Department of Horticulture, Beijing Vocational College of Agriculture, Beijing, 102442, China

guoyibvca@163.com

Keywords: sprout; tide-type irrigation; design system; SolidWorks; redevelopment

\begin{abstract}
To solve problems of uneven growth of sprouts due to unevenness of irrigation in sprout production, severe waste of water resources and poor marketability, a sprout tide-type irrigation device has been designed. This device can guarantee sprouts demand for moisture, enable even growth of sprouts and improve marketability. Besides, it can realize automatic irrigation and save water resources, to save labor cost. The sprout tide-type irrigation device design system has been designed using the SolidWorks redevelopment interface and Visual Basic development platform. This has simplified the originally complicated design work, shortened design period and improved product development efficiency. It can solve the problems of sprout tide-type irrigation device design and material calculation. It has provided a convenient design method to users and basis for material purchase and manufacturing to producers.
\end{abstract}

\section{Introduction}

Sprouts have fresh and tender mouthfeel and contain multiple amino acids, mineral substances and vitamins, so they feature multiple health protection functions. Besides, they have a shorter production cycle, higher efficiency, less investment, fast effect but higher earnings, thus presenting a wide market prospect [1]. Today, in sprout production, irrigation usually adopts the sprinkling irrigation method, which has great loss from water leakage and evaporation, causes severe waste of water resources and features poor irrigation evenness, thereby to lead to unevenness of sprout growth and poor marketability [2].

The tide-type irrigation is a water-saving irrigation technology, which enables irrigation from the cultivation container bottom [3]. It works in the way that water or fertilizer is delivered through the closed pipeline to the cultivation container bottom on the tide, while on the ebb-tide, water or fertilizer returns through the pipeline. The filtered water or fertilizer can be reusable [4]. The tide-type irrigation can effectively improve water resource utilization ratio, save water, reduce the seedbed moisture, enhance plant growth speed and solve such problems existing in the traditional top irrigation as sever waste of water, uneven irrigation and too great humidity of the seedbed $[5,6]$. Currently most tide-type irrigation systems used in China are directly imported. Related research on this field has just started $[7,8]$.

SolidWorks is excellent machine design software that can be used for designing all related 3D entity models and assembly models. To facilitate users' redevelopment, SolidWorks has furnished several hundred of API functions that work as interfaces for development languages such as Basic, $\mathrm{C}^{++}$and other OLE-supporting languages and features favorable development ability and compatibility. Most functions of SolidWorks can be realized through calling SolidWorks API commands. Redevelopment can simply the originally complicated design work, shorten design period and enhance product development efficiency. With the SolidWorks redevelopment method, Guo Yi [9] developed a sprout vertical cultivation device design system, Li Weiliang [10] and et al. implemented parameterized design of hydraulic cylinders, Guo Ying [11] and et al. redeveloped parameterized modules of the housing case of the industrial flat bed sewing machine, Li Zhenhua [12] and et al. realized parameterized modeling of the springs for housing box of the $\mathrm{CRH}$, Chen Tian [13] and et al. developed the metering pump fast design system, Sun Zhiyang [14] and et al. developed a vertical pot fast design system, and Song Qi [15] and et al. realized 3D parameterized 
design of main parts for common roller of the conveyer.

To solve problems in the plant growth process, a sprout tide-type irrigation device has been designed to realize automatic irrigation, meet water need from sprouts, realize even irrigation, thereby to make sprout grow evenly and improve marketability. A sprout tide-type irrigation device design system has also been designed, which can make 3D modeling of the device according to the growth scale of sprouts and also work out quantity of materials required for manufacturing the device. It has provided a convenient design method to users and basis for material purchase and manufacturing to producers.

\section{Overall Structure of the Sprout Tide-type Irrigation Device}

The sprout tide-type irrigation device has adopted a multi-layer vertical cultivation model to raise the space utilization ratio. Its trapezoidal structure enables sufficient sunshine for each layer of sprouts, so that $n$ the sprout growth process in the sunlight greenhouse, no supplemental lighting equipment will be needed, to save the energy required by supplemental lighting. This device is composed of the rack, water tank, water pump, water inlet pipe, return pipe, filter, magnetic vale, cultivation tank, seedling tray and control system (Fig.1). The rack is used to install the cultivation tank, water inlet pipe and return pipe. The water tank stores irrigation water. The water pump is designed to pressurize the water and supply water to the water inlet pipe. The water inlet pipe is used to supply water to the cultivation tank. The return pipe is designed to enable water from the cultivation tank to flow back to the recovery tank. The filter is to eliminate impurities in the return water. The cultivation tank is designed for placing seedling trays and storing the irrigation water, the seedling tray for cultivating sprouts, the magnetic valve for controlling back flow of water from the cultivation tank and the control system for controlling the fixed-time work of the water pump and the magnetic valve.

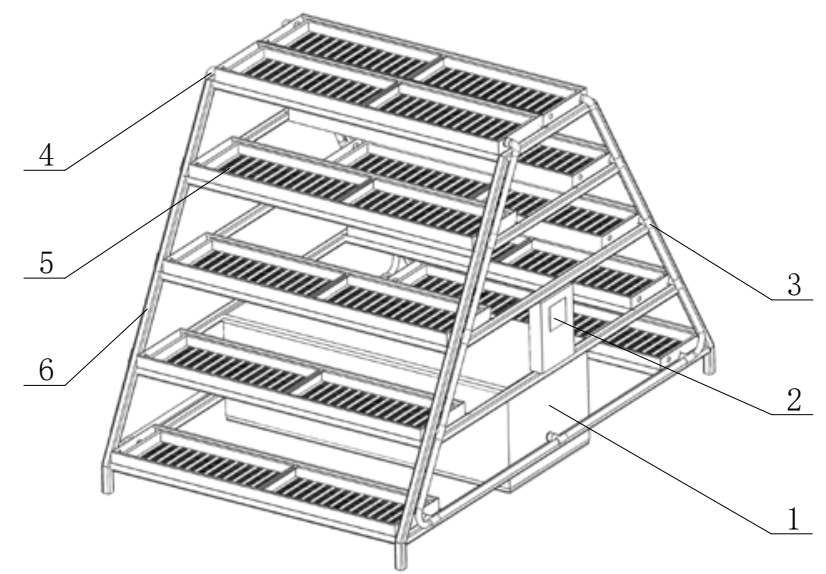

1-water tank 2-control system 3- water inlet pipe rack 4- return pipe 5- cultivation tank 6- rack

Fig. 1 Sprout tide-type irrigation device

\section{Development Process of the Design System}

The design system is developed in the following steps: first, use SolidWorks to build a 3D model for spare parts; second, use Visual Basic to write the redevelopment program of SolidWorks to realize rebuilding of the $3 \mathrm{D}$ model of the device and at the same time work out the quantity of materials required for making the device.

\section{Establishment of the 3D Model}

Establishment of the 3D Model of the Rack. The rack has a trapezoidal rack composed of the side and the crossbeam, with the side welded with the stainless steel square tube and the crossbeam adopting the angle steel. The side and the crossbeam are bolted together. The weld modules in SolidWorks are used for 3D modeling of the rack (Fig.2). 


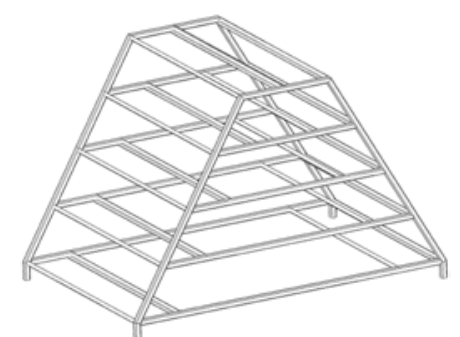

Fig. 2 Rack

Establishment of the 3D Model of the Water Tank. The water tank has a rectangular cabinet structure composed of the cabinet and the tank cover. On one side of the cabinet is a water inlet pipe mounting hole and on the other a return pipe mounting hole. The metal plate modules in SolidWorks are used for 3D modeling of the water tank (Fig.3).

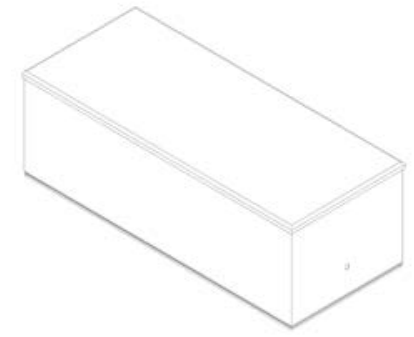

Fig. 3 Water tank

Establishment of the 3D Model of the Cultivation Tank. The cultivation tank has a rectangular cabinet structure with the opening in the upper, one side having the water inlet pipe mounting hole and the other side the return pipe mounting hole. The cultivation tank is used to placing seedling trays. To ensure ventilation of the sprout roots, the cultivation handle has a support rod. The 3D model of the cultivation tank is shown in Fig.4.

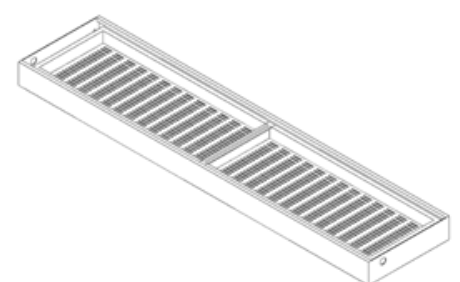

Fig. 4 cultivation tank

Establishment of the 3D Models of the Water Inlet pipe and the Return Pipe. The water inlet pipe and the return pipe adopt PVC-U water pipes and are connected with tee joints, elbows and pipe fittings. Their 3D models are shown in Fig.5.

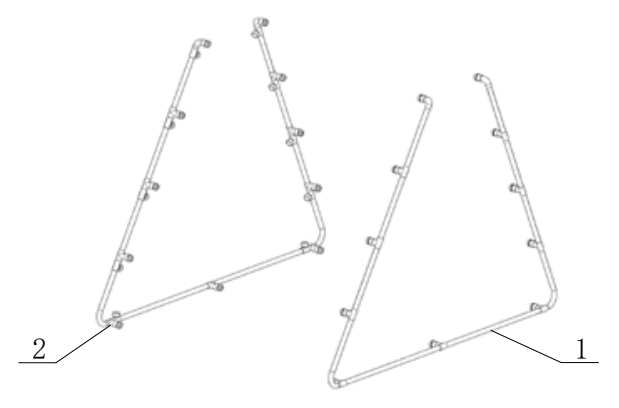

1-water inlet pipe 2-return pipe

Fig. 5 Water inlet pipe and return pipe

Establishment of the 3D Models of the Magnetic Valve and the Water Pump. The magnetic valve adopts DN 15 normally-closed magnetic valve as the water valve and the water pump adopts the submersible pump. They are common parts and have the 3D modeling according to their structural parameters.

Establishment of the 3D Model of the Assemblage. After the 3D models of parts are built, use the assembly function of SolidWorks to add the coincided, concentric and tangential relations to spare parts for assembly. The interference check function of SolidWorks is used to check the 
interference problems in 3D model assembly. The 3D model of the assemblage of the device is obtained (Fig.1).

\section{Development of the Design System}

The design system is developed using the SolidWorks redevelopment interface and the Visual Basic development platform. Applications include the user interface, redevelopment modules and material computation modules. The user inputs design parameters on the user interface. The redevelopment module calls API functions of SolidWorks, to realize rebuilding of the 3D models of spare parts. In addition, the material computation module calculates quantity of materials required and displays it on the user interface.

\section{Application Example}

Beijing Green Valley Sprouts Co., Ltd. has utilized this system to design a five-layer sprout tide-type irrigation device, with each layer holding 6 seedling trays. First, input design parameters on the user interface: 5 layers; 570mm long, 240mm wide, 32mm high seedling trays; 6 seedling trays on each layer; 300mm interlayer spacing; rack inclination $60^{\circ}$. Then, click the "3D model update" button to start the SolidWorks, which will automatically reestablish 3D models of spare parts and assemblage according to design parameters input by the user, to produce the 3D model of the sprout tide-type irrigation device (Fig.6). Then, click "Material computation" button so that the system will automatically calculate the quantity of materials required, including length of the rack square tube, steel plate area of the water tank, steel plate area of the cultivation tank, length of PVC-U water pipe, number of tee joints/elbows/ pipe fittings /magnetic valves, and pump lift. The calculation results are shown in Fig.7.

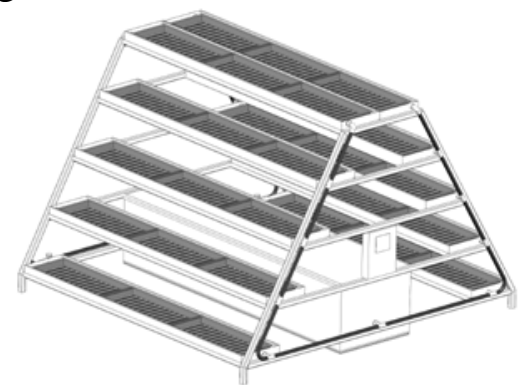

Fig. 6 3D model of the sprout tide-type irrigation device

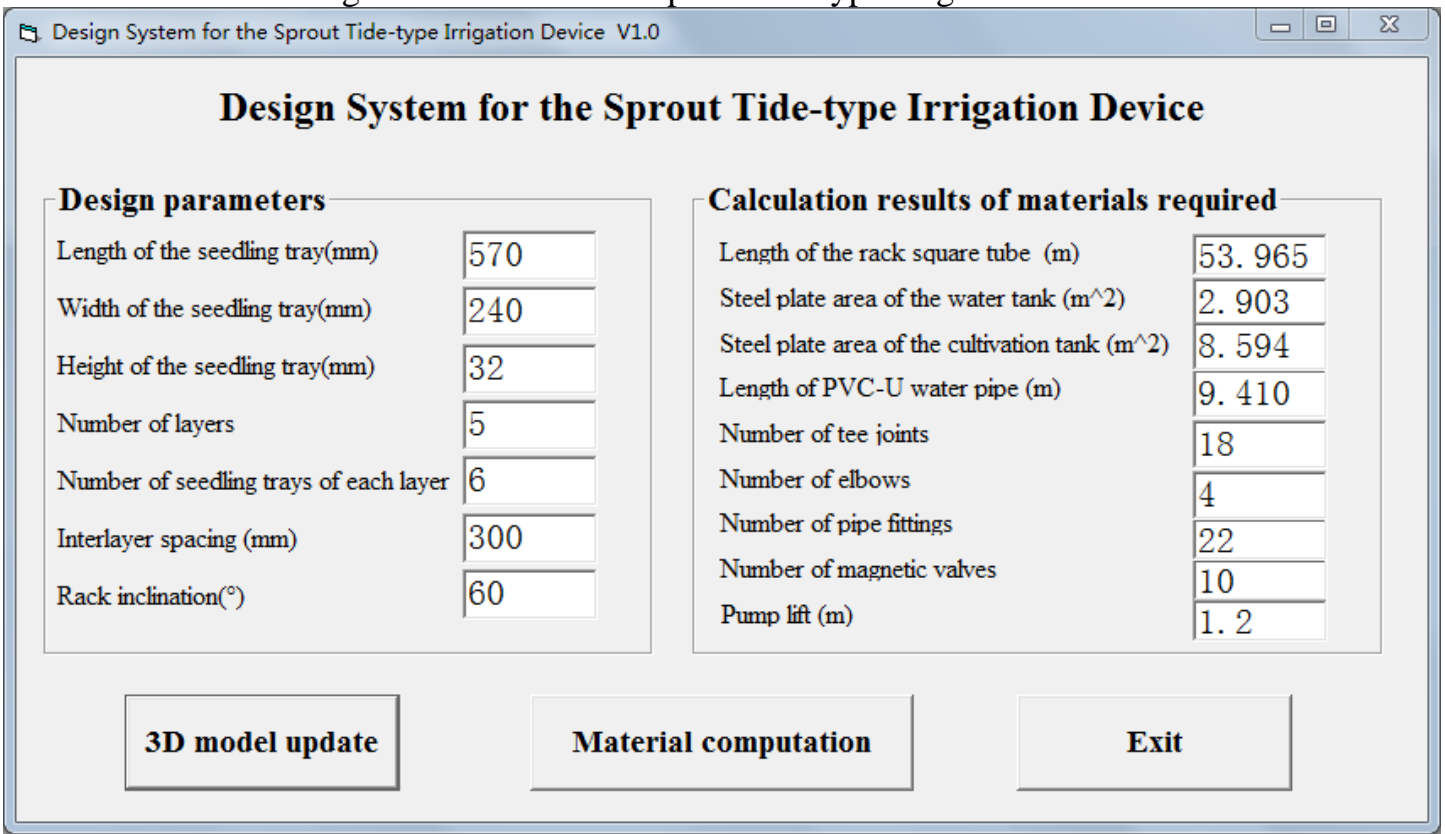

Fig. 7 Design System for the Sprout Tide-type Irrigation Device 


\section{Conclusion}

The sprout tide-type irrigation device has been designed with the tide-type irrigation technology to realize vertical cultivation of sprouts and improve space utilization ratio. This device can guarantee sprouts demand for moisture, produce even irrigation and enable even growth of sprouts and improve marketability. Besides, it can realize automatic irrigation and save water resources, to save labor cost.

The sprout tide-type irrigation device design system has been designed using the SolidWorks redevelopment interface and Visual Basic development platform. This has simplified the originally complicated design work, shortened design period and improved product development efficiency.

The application example has indicated that the system can realize automatic reestablishment of 3D models of spare parts and assemblage according to design parameters input by the user and at the same time work out quantity of materials required. The system interface is user-friendly, easy to operation and able to realize its functions. It can solve the problems of sprout tide-type irrigation device design and material calculation. It has provided a convenient design method to users and basis for material purchase and manufacturing to producers.

\section{Acknowledgements}

This paper is funded by "Water-saving Irrigation Technology in the Production of Sprouts" project (Project No. 20150203-13) under Beijing Municipal Commission of Rural Affairs.

\section{References}

[1] GUO Yi, Chen Lanfen, Suo Lang Jin Zong, Yang Zhen. Design of Sprout Aeroponics Equipment[J]. Advances in Engineering Research, 2016, (88): 1783-1789.

[2] GUO Yi, Chen Lanfen, Zhang Guiqin. Design of a Sprout Layer-rack Aeroponic Cultivation Device[J]. Advances in Engineering Research, 2016, (104): 395-400.

[3] GAO Yanmin g, LIU Hongjiu, ZHENG Jiaqi, LI Jianshe. Study on Ebb and Flow Irrigation of Cucumber Plug Seedlings[J]. Journal of Irrigation and Drainage, 2016, (01): 79-82.

[4] CHEN Minghui, HUANG Danfeng, ZHU Lanjuan. Study of Tidal Irrigation Strategy for Vegetable Seedlings Based on Neural Networks[J]. Journal of Changjiang Vegetables, 2014, (22) :38-41.

[5] WANG Kelei, ZHOU Youhe, SHI Jianlei, HUANG Zong'an, ZHU Longjing, XU Jian. Application of dynamic water level management of ebb and flow irrigation for cucumber seedlings[J]. Acta Agriculturae Zhejiangensis, 2017, 29( 3) : 408-413.

[6] LIU Hongjiu, GAO Yanming, SHEN Fu, XU Sumeng, LI Jianshe. The ebb and flow irrigation technology for tomato plug seedlings[J]. Journal of Anhui Agricultural University, 2015, (04): 549-554.

[7] WU Junhui, HUANG Rongrong, CHEN Jie, SI Huiping, LIN Kaiyan, DONG Miao, ZHENG Yong. Design and Realization of the Ebb-and-flow Irrigation Control System[J]. Electronic Science and Technology, 2016, (11): 54-58.

[8] LIU Hongjiu, GAO Yanming, LI Jianshe. Research and Development on Ebb-and-flow Irrigation Technique[J]. Northern Horticulture, 2014, (10): 174-176.

[9] Guo Yi, Zhang Guiqin. Development of A Design System for the Sprout Vertical Cultivation Device [J]. Advances in Engineering Research, 2015,(26): 206-211.

[10] LI Weiliang, WANG Yixiang. Parametric Design of Hydraulic Cylinder with Secondary Development Based on Solidworks[J]. Machine Building \& Automation. 2017, (01): 74-77. 
[11] GUO Ying, CAO Ju-jiang, ZHANG Ke-yu. Parametric Design Based on SolidWorks for Industrial Sewing Machine Casing[J]. Mechanical Engineering \& Automation, 2016, (03): 24-25.

[12] LI Zhenhua, SHANG Yuejin, WANG Hong. Parametrization design of EMU spring based on secondary development of SolidWorks[J]. Computer Aided Engineering, 2015, (05): 38-41.

[13] CHEN Tian, CHEN Haipeng, YIN Song, LI Lin, XU Fuchun. Rapid Design System of Metering Pump Based on SolidWorks[J]. Journal of Shanghai Dianji University, 2016, (02): 70-75.

[14] SUN Zhiyang, ZHONG Liangwei, LU Kangdong, SHI Hailin. The Research of Rapid Design System for the Vertical Tank System Based on SolidWorks Secondary Development[J]. Telecom Power Technology, 2015, (06): 64-66.

[15] SONG Qi, ZHANG Liangyou. Research and Application of 3D Design Technology For Conveyor Components[J]. Mechanical Engineering \& Automation, 2015, (04): 27-29. 